University of Nebraska - Lincoln

DigitalCommons@University of Nebraska - Lincoln

\title{
Uranium Extraction From Laboratory-Synthesized, Uranium-Doped Hydrous Ferric Oxides
}

\author{
Steven Smith \\ Pacific Northwest National Laboratory, steven.smith@pnl.gov \\ Matthew Douglas \\ Pacific Northwest National Laboratory \\ Dean A. Moore \\ Pacific Northwest National Laboratory \\ Ravi K. Kukkadapu \\ Pacific Northwest National Laboratory, ravi.kukkadapu@pnl.gov \\ Bruce Arey \\ Pacific Northwest National Laboratory
}

Follow this and additional works at: https://digitalcommons.unl.edu/usdoepub

Part of the Bioresource and Agricultural Engineering Commons

Smith, Steven; Douglas, Matthew; Moore, Dean A.; Kukkadapu, Ravi K.; and Arey, Bruce, "Uranium Extraction From Laboratory-Synthesized, Uranium-Doped Hydrous Ferric Oxides" (2009). US Department of Energy Publications. 151.

https://digitalcommons.unl.edu/usdoepub/151

This Article is brought to you for free and open access by the U.S. Department of Energy at DigitalCommons@University of Nebraska - Lincoln. It has been accepted for inclusion in US Department of Energy Publications by an authorized administrator of DigitalCommons@University of Nebraska - Lincoln. 


\section{Uranium Extraction From Laboratory-Synthesized, Uranium-Doped Hydrous Ferric Oxides}

\author{
STEVEN C. SMITH, * MATTHEW DOUGLAS, \\ DEAN A. MOORE, RAVI K. KUKKADAPU, \\ AND BRUCE W. AREY \\ Pacific Northwest National Laboratory, Richland, \\ Washington 99354
}

Received September 25, 2008. Revised manuscript received January 12, 2009. Accepted February 10, 2009.

The extractability of uranium (U) from synthetic uranium - hydrous ferric oxide (HFO) coprecipitates has been shown to decrease as a function of mineral ripening, consistent with the hypothesis that the ripening process will decrease uranium lability. To evaluate this process, three HFO suspensions were coprecipitated with uranyl $\left(\mathrm{UO}_{2}{ }^{2+}\right)$ and maintained at $\mathrm{pH} 7.0 \pm 0.1$. Uranyl was added to the HFO postprecipitation in a fourth suspension. Two suspensions also contained either coprecipitated silicate ( $\mathrm{Si}-\mathrm{U}-\mathrm{HFO}$ ) or phosphate (P-U-HFO). After precipitation of the HFOs, at time intervals of 1 week, 1 month, 6 months, 1 year, and 2 years, aliquots of each suspension were contacted with five extractant solutions for a range of time. Uranium was preferentially extracted over Fe in varying degrees from all coprecipitates, by all extractants. The preference was dependent on the duration of mineral ripening and adjunct anion. Micro-X-ray diffraction analysis provides evidence for the transformation from amorphous material to phases containing substantial proportions of crystalline goethite and hematite, except the $\mathrm{P}-\mathrm{U}-\mathrm{HFO}$, which remained primarily amorphous. Analysis of the U-HFO coprecipitate by the Mössbauer technique and scanning electron microscopy provides confirmation of an increase in particle size and evidence of mineral ripening to crystalline phases.

\section{Introduction}

Uranium (U) is ubiquitous in the natural environment, is associated with soils and sediments, and has an average crustal abundance of $2.7 \mathrm{mg} / \mathrm{kg}$ (1). The mineral and physicochemical relationship of $U$ with soil varies from aqueous species $(2-4,5,6,7)$ to sorbed, readily exchangeable, oxidized species, such as uranyl $\left[\mathrm{U}\left(\mathrm{VI} \mathrm{O}_{2}{ }^{2+}\right]\right.$, to highly insoluble $\mathrm{U}(\mathrm{VI})$-bearing minerals and phases containing reduced $[U(I V)](8,9)$. U species will participate in a range of geochemical reactions that may alter the original chemical form, resulting in more thermodynamically stable aqueous and solid phases under ambient environmental conditions $(2,3,10,11)$. As a first step toward subsequent physicochemical transformation, sorption is a rapid mechanism that retards the translocation of uranyl within the soil profile. Moreover, the formation of highly insoluble and environmentally stable phases significantly retards U mobility and

* Corresponding author phone: (509) 376-0216; fax: (509) 3765021; e-mail: steven.smith@pnl.gov. may be highly desirable for purposes of environmental remediation $(12,13)$. In one such mechanism, Allard et al. (14) reported the formation of U-bearing silicon, aluminum, and iron (Fe) gels resulting from weathering of granitic material, while Duff et al. (15) reported on the coprecipitation of $U$ with iron oxide minerals. Of particular interest is the transformation of amorphous U-bearing minerals to stable, crystalline forms (16) as this will impact remediation strategies.

When contaminant $U$ is associated with soil, it has the opportunity to coprecipitate with dissolved ions, including ubiquitous Si and P species, from soil solution to form mineral phases of various composition and crystallinity. For example, $\mathrm{U}$-phosphorus phases were identified in contaminated soil at the Fernald site in Ohio (17). The initial precipitates may be relatively unstable and subsequently transform to phases of greater stability $(10,16,18,19)$. Freshly precipitated mineral phases are known to increase in crystallinity as time progresses; this phenomenon is termed Ostwald ripening $(20,21)$. This term also refers to the increase in crystallite size that occurs over time at the expense of smaller crystallites in the system and may include a reduction in the amount of associated water. The net effect is that the solubility of the dominant mineral phases decreases with time because the surface area:volume ratio is reduced. This process involves dynamic in situ dissolution and reprecipitation of the solid and is termed mineral ripening in this report. Thus, the surface is constantly changing and providing opportunity for contaminant ions to be incorporated into the bulk structure.

Previous studies have shown that the reversibility of metal ion sorption to inorganic mineral phases decreases as the metal-mineral association ages $(22,23)$. Several explanations for such behavior have been made, including the possibility of slow diffusion of metal ions into and out of the solid, restructuring of the solid surface that is dependent on the presence of adsorbate, and incorporation of metal ions into the crystal structure. For example, Duff et al. (15) reported the direct incorporation of $U$ into Fe oxide. Each of these phenomena would result in the metal ions being less accessible to a surrounding aqueous phase, thus lowering the probability that such ions will be extracted from the solid. However, the role of common groundwater anions, such as $\mathrm{P}$ or Si species, on the rate and extent of Fe oxide transformation and sequestration of associated metal species is poorly understood. Furthermore, natural weathering and redox cycles may effect changes in the surface and bulk properties of soil components and critical properties of the soil solution, which influence the physical and chemical behavior of associated contaminants. Consequently, the reversibility of $U$ sorption may change as a function of the time that it has been associated with sediment. This phenomenon is frequently observed and has been reported as an increase of the dissociation constant, or $K_{d}$, and has been attributed to diffusion into cracks or pores on the particle surface or interaggregate sequestration $(2,3)$.

Application of selective extraction methodologies (24) may provide insight into the changes of the mineral phase as a function of ripening, subsequent impacts on extractability of coprecipitated elements, and the distribution of these elements in the mineral lattice. However, one must not overinterpret the results of either single or sequential extractions (25).

ThisarticlereportstheextractabilityofUfromuranium-hydrous ferric oxide (HFO) as a function of mineral ripening using various extractants. Fresh HFO precipitates were selected 

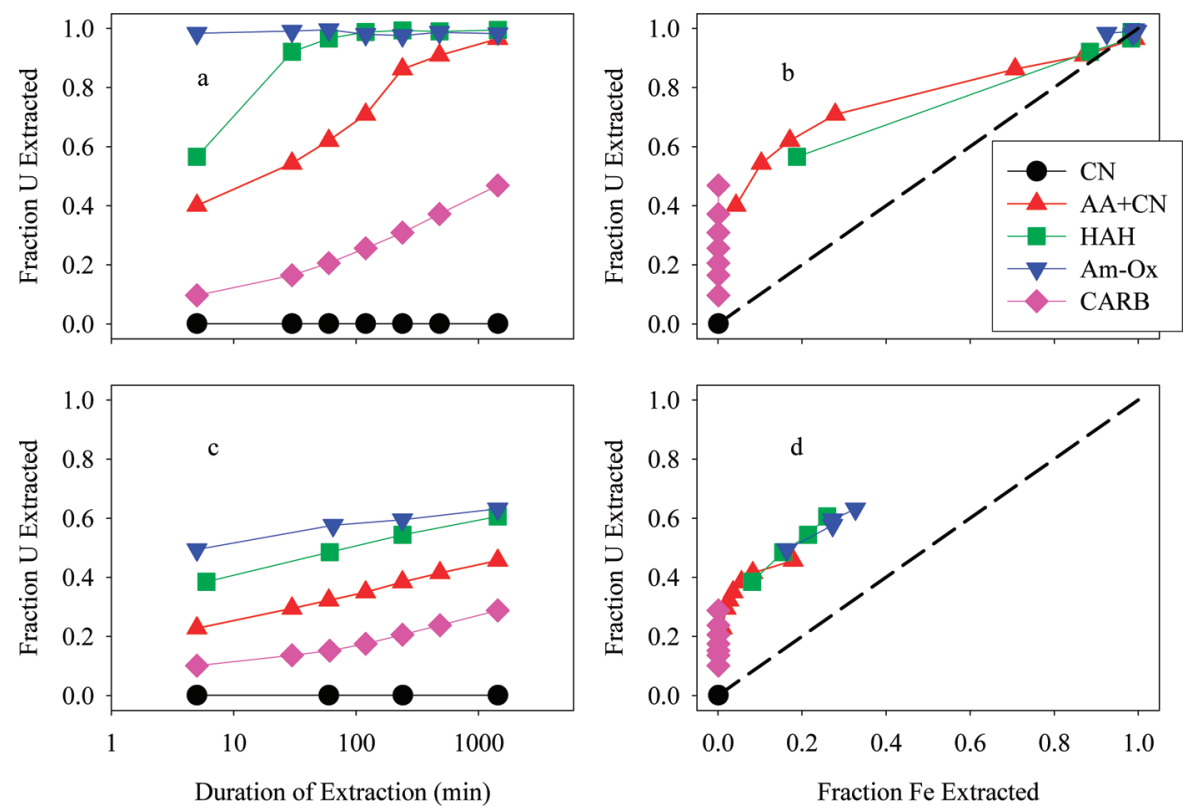

FIGURE 1. Uranium and iron extracted from the U-HFO coprecipitate after ripening for 1 month (a, b) and 2 years (c, d). Extractants: $\mathrm{CN}=$ calcium nitrate, $\mathrm{AA}+\mathrm{CN}=$ acetic acid and calcium nitrate, $\mathrm{HAH}=$ hydroxylamine hydrochloride and nitric acid, Am-0x $=$ ammonium oxalate and oxalic acid, and CARB = sodium bicarbonate and sodium carbonate. The diagonal dashed lines in (b) and (d) indicate congruent extraction.

TABLE 1. Concentrations of Iron, Uranium, Phosphate, and Silicate in the HFO Suspensions ${ }^{a}$

\begin{tabular}{|c|c|c|c|c|}
\hline \multicolumn{4}{|c|}{ concentration (mol/L) } & \multirow[b]{2}{*}{ comment } \\
\hline $\mathrm{Fe}$ & $\mathbf{U}$ & $\mathbf{P}$ & Si & \\
\hline $\begin{array}{l}5 \times 10^{-2} \\
5 \times 10^{-2} \\
5 \times 10^{-2} \\
5 \times 10^{-2}\end{array}$ & $\begin{array}{l}5 \times 10^{-7} \\
5 \times 10^{-7} \\
5 \times 10^{-7} \\
5 \times 10^{-7}\end{array}$ & $\begin{array}{l}0 \\
5 \times 10^{-5} \\
0 \\
0\end{array}$ & $\begin{array}{l}0 \\
0 \\
5 \times 10^{-5} \\
0\end{array}$ & $\begin{array}{l}\text { Fe and } U \text { coprecipitated } \\
\text { Fe, U, and P coprecipitated } \\
\text { Fe, U, and Si coprecipitated } \\
U \text { added after precipitation of HFO }\end{array}$ \\
\hline
\end{tabular}

${ }^{a}$ Suspension $\mathrm{pH}$ maintained at $7.0 \pm 0.1$. The background electrolyte is approximately $0.15 \mathrm{~mol} / \mathrm{L}$ sodium nitrate.

for study due to their presence in soils and sediments, their known affinity for dissolved $U$, and because previous studies demonstrated a transformation of the mineral phase as a function of ripening $(23,26)$. Multiple solid phases were synthesized in the laboratory and extracted following select periods of ripening. In addition to the chemical extractions, the coprecipitates were characterized by micro-XRD, Mössbauer spectroscopy, and scanning electron microscopy (SEM). The results show that $U$ and Fe extractability decreases as the HFOs transform with time. Therefore, the sequestration of dissolved $U$ by coprecipitation with Fe oxide may provide a significant, long-term sink for contaminant U in soil.

\section{Methods}

Preparation of HFO Suspensions. A synthetic coprecipitate of the isotope ${ }^{233} \mathrm{U}$, as uranyl nitrate (CRM 111-A, New Brunswick National Laboratory, Argonne, IL), and HFO (U-HFO) was prepared by dissolving ferric nitrate $(>99.999 \%$ purity) in deionized water $(5 \mu \mathrm{S} / \mathrm{cm})$ and subsequent precipitation by addition of dissolved sodium hydroxide ( $\mathrm{NaOH} ;>99.99 \%$ purity) to $\mathrm{pH} 7.0 \pm 0.1$ with constant stirring (27). The procedure minimizes the presence of dissolved $\mathrm{CO}_{2}$ during precipitation by sparging $\mathrm{N}_{2(\mathrm{~g})}$ for approximately $1 \mathrm{~h}$ prior to addition of $\mathrm{NaOH}$. The $\mathrm{P}-\mathrm{U}-\mathrm{HFO}$ coprecipitate was prepared as described above, except that both ${ }^{233} \mathrm{U}$ and disodium hydrogen phosphate $\left(\mathrm{Na}_{2} \mathrm{HPO}_{4} \cdot 7 \mathrm{H}_{2} \mathrm{O}\right)$ were included in the solution prior to $\mathrm{pH}$ adjustment. The $\mathrm{Si}-\mathrm{U}-\mathrm{HFO}$ was also prepared as described above, except that $\mathrm{Si}$ was included in place of $\mathrm{P}$. In the latter case, sodium metasilicate $\left(\mathrm{Na}_{2} \mathrm{SiO}_{3} \cdot 9 \mathrm{H}_{2} \mathrm{O}\right)$ was dissolved in $\mathrm{NaOH}$ solution prior to its addition to the Fe $+\mathrm{U}$ solution. Lastly, a suspension of HFO was prepared without $U$, and two days after the initial precipitation ${ }^{233} \mathrm{U}$ was added to the suspension. This material is designated as $\mathrm{HFO}+\mathrm{U}$ hereafter. A single batch suspension of each precipitate was prepared, and subsamples were removed at specific time intervals (described later). Table 1 summarizes the target $\mathrm{Fe}, \mathrm{U}, \mathrm{Si}$, and $\mathrm{P}$ concentrations in the four suspensions which were incubated at ambient laboratory conditions $\left(22-23{ }^{\circ} \mathrm{C}\right.$ and atmosphere). Analysis of the suspensions confirmed the element concentrations were achieved within $10 \%$ of the target. In all suspensions, the aqueous concentration of the salt $\mathrm{NaNO}_{3}$ is approximately $0.15 \mathrm{~mol} / \mathrm{L}$, and, following precipitation of the solid phases, dissolved $U$ and Fe were below detection. The analytical detection limits for ${ }^{233} \mathrm{U}$ and Fe were $0.1 \%$ and $0.2 \%$, respectively, of the total present.

Preparation of Extractants. Extracting solutions were prepared as described by Sowder et al. (28) and Kohler et al. (29). The calcium nitrate $(\mathrm{CN})$ extractant $\left[0.5 \mathrm{~mol} / \mathrm{L} \mathrm{Ca}\left(\mathrm{NO}_{3}\right)_{2}\right.$, $\mathrm{pH}$ 6.1] targets the extraction of exchangeable, uraniumbearing cation species. The acetic acid + calcium nitrate (AA $+\mathrm{CN})$ extractant $[0.44 \mathrm{~mol} / \mathrm{L}$ acetic acid $+0.1 \mathrm{~mol} / \mathrm{L}$ $\mathrm{Ca}\left(\mathrm{NO}_{3}\right)_{2}, \mathrm{pH}$ 2.6] dissolves weak-acid soluble oxides. The hydroxylamine hydrochloride + nitric acid $(\mathrm{HAH})$ extractant $\left[0.01 \mathrm{~mol} / \mathrm{L} \mathrm{NH}_{2} \mathrm{OH} \cdot \mathrm{HCl}+0.1 \mathrm{~mol} / \mathrm{L} \mathrm{HNO}_{3}, \mathrm{pH}<1\right]$ dissolves weak-acid soluble and amorphous oxides. The ammonium 


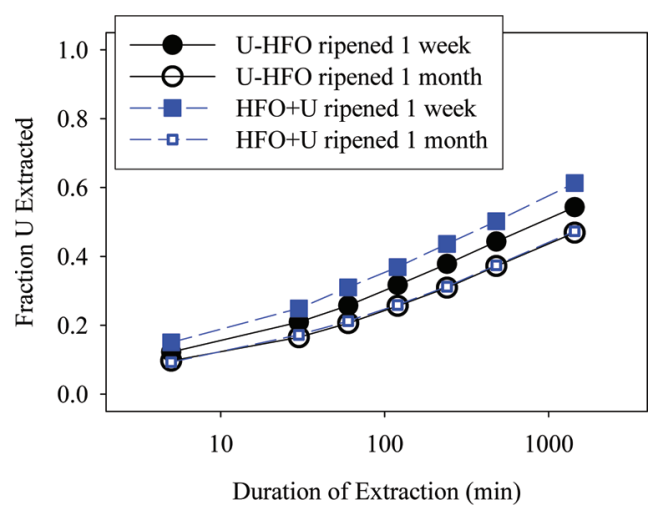

FIGURE 2. Uranium extracted from the U-HFO coprecipitate and the HFO $+U$ using the CARB extractant after ripening for 1 week and 1 month.

oxalate + oxalic acid (Am-Ox) extractant $[0.2 \mathrm{~mol} / \mathrm{L}$ ammonium oxalate $+0.1 \mathrm{~mol} / \mathrm{L}$ oxalic acid, $\mathrm{pH} 3.3$ ] dissolves noncrystalline oxides, and the extraction was performed in light-excluded containers. The sodium bicarbonate + sodium carbonate (CARB) solution $\left[0.014 \mathrm{~mol} / \mathrm{L} \mathrm{NaHCO}_{3}+0.0028\right.$ $\mathrm{mol} / \mathrm{L} \mathrm{Na}_{2} \mathrm{CO}_{3}$, pH 9.4] extracts labile U.

Sampling and Analysis. The U-HFO, P-U-HFO, and $\mathrm{Si}-\mathrm{U}-\mathrm{HFO}$ suspensions were sampled at 1 week, 1 month, 6 months, 1 year, and 2 years after the initial precipitation. Samples of the solution phase were obtained to determine aqueous concentrations of $\mathrm{U}$ and $\mathrm{Fe}$. In general, extractions were performed by combining a $2 \mathrm{~mL}$ aliquot of the suspension with $8 \mathrm{~mL}$ of extractant and mixing for various contact times $(5 \mathrm{~min}, 30 \mathrm{~min}, 1 \mathrm{~h}, 2 \mathrm{~h}, 4 \mathrm{~h}, 8 \mathrm{~h}, 24 \mathrm{~h}$ for all extractants, and approximately 20 days for the CARB extractant) using a benchtop rocker-style shaker. The HFO + $\mathrm{U}$ system was sampled after 1 week, 1 month, and 6 months of mineral ripening.

Phase separation of the solid phase from the dissolved (extracted) components was accomplished by transferring the suspension to a plastic syringe fitted with a $0.2 \mu \mathrm{m}$ filter (HT Tuffryn membrane). Fe in the filtrate was determined by inductively coupled plasma-optical emission spectroscopy (ICP-OES). ${ }^{233} \mathrm{U}$ in the filtrate was analyzed using either ICP-mass spectroscopy or liquid scintillation counting.

Solid Phase Characterization. Images of the fresh (4 days old) and ripened (approximately 28 months) U-HFOs were obtained using SEM. Mössbauer spectroscopy of fresh and aged U-HFO was performed to quantify the multiple iron oxide phases in each material (Figure S2). X-ray diffraction patterns of the fresh $\mathrm{U}-\mathrm{HFO}$ and ripened $\mathrm{U}-\mathrm{HFO}, \mathrm{P}-\mathrm{U}-\mathrm{HFO}$, and $\mathrm{Si}-\mathrm{U}-\mathrm{HFO}$ provided further information regarding the proportion and type of transformation products (Figure S1). Details of the methods used for SEM, Mössbauer spectroscopy, and X-ray diffraction are presented in the Supporting Information.

\section{Results and Discussion}

Solid Phase Characterization. Thermodynamic modeling of each system at pH 7 was conducted using MINTEQ (30). In all cases the model predicted the formation of hematite $\left(\mathrm{Fe}_{2} \mathrm{O}_{3}\right)$. In the $\mathrm{U}-\mathrm{HFO}$ and $\mathrm{Si}-\mathrm{U}-\mathrm{HFO}$ systems, the model predicted that $100 \%$ of the $U$ remains dissolved and the predominant $\mathrm{U}$ species are $\left(\mathrm{UO}_{2}\right)_{2} \mathrm{CO}_{3}(\mathrm{OH})_{3}{ }^{-}(80 \%)$ and $\mathrm{UO}_{2} \mathrm{CO}_{3}{ }^{0}(9 \%)$, with minor amounts of $\mathrm{UO}_{2} \mathrm{OH}^{+}(3 \%)$ and $\mathrm{UO}_{2} \mathrm{OH}_{2}{ }^{0}$ (3\%). However, in the system with $\mathrm{P}$, the model predicted that sodium autinite $\left[\mathrm{Na}_{2}\left(\mathrm{UO}_{2}\right)_{2}\left(\mathrm{PO}_{4}\right)_{2} \cdot 10-12 \mathrm{H}_{2} \mathrm{O}\right]$ precipitates and controls the aqueous concentration of $\mathrm{U}$, and the balance of $\mathrm{P}$ is dissolved $\mathrm{HPO}_{4}{ }^{2-}(47 \%), \mathrm{H}_{2} \mathrm{PO}_{4}{ }^{-}(28 \%)$, and $\mathrm{NaHPO}_{4}{ }^{-}(22 \%)$. In the system with $\mathrm{Si}$, the predominant
Si specie is dissolved, neutral $\mathrm{H}_{4} \mathrm{SiO}_{4}$. It is likely that the method used in this study to synthesize coprecipitates with homogeneous distributions of elements yields chemical forms that MINTEQ could not accurately predict.

The X-ray diffraction pattern of fresh $\mathrm{U}-\mathrm{HFO}$ is characteristic of amorphous two-line ferrihydrite (31). The ripened $\mathrm{U}-\mathrm{HFO}$ and $\mathrm{Si}-\mathrm{U}-\mathrm{HFO}$ contain goethite and hematite, two crystalline iron oxides common in the natural environment in addition to ferrihydrite. The diffraction pattern of $\mathrm{P}-\mathrm{U}-\mathrm{HFO}$ indicates the solid phase remains primarily amorphous. These results are not consistent with those reported by Gálvez et al. (32), where $>0.5 \% \mathrm{P} /$ Fe mol ratio was required to inhibit the formation of crystalline forms of Fe oxide. A potential explanation is that subtle differences in the preparation and aging conditions, or the combined effect of $U$ and $P$ in the system, may yield dissimilar results. $\mathrm{X}$-ray diffraction patterns of the fresh $\mathrm{U}-\mathrm{HFO}$ and ripened coprecipitates are in the Supporting Information (Figure S1). The relative extractability of Fe from these materials (discussed in the Supporting Information) supports these results, in that Fe is more easily extracted from amorphous phases than from crystalline phases.

The Mössbauer spectra of the fresh (10-day) U-HFO at room temperature (RT) (Figure S2a) and liquid nitrogen (77 K; figure not shown) are typical of two-line ferrihydrite (19), in agreement with the micro-XRD data (Figure S1a). Mössbauer features of both goethite and hematite, however, are dictated by their particle size (33). "Large" particle goethite $(>15-20 \mathrm{~nm})$ and hematite $(>8 \mathrm{~nm})$ display sextet features at RT, while smaller particles appear as doublets at RT and as sextets at $77 \mathrm{~K}$ (33). Thus, the absence of sextet peaks in the $77 \mathrm{~K}$ spectrum indicate the 10-day HFO was devoid of even small amounts $(<1 \%)$ of goethite and hematite. The RT Mössbauer spectrum of the 16-month ripened U-HFO includes the doublet feature and two sets of sextets typical of large particle goethite and hematite (Figure S2b). These results are in good agreement with the XRD pattern (Figure S1b).

SEM images of the fresh (approximately 4 days) and ripened (approximately 28 months) U-HFO coprecipitates are shown in Figures S3a and S3b, respectively. The morphology of the fresh $\mathrm{U}-\mathrm{HFO}$ particles is small spheroids, $20-30 \mathrm{~nm}$ in diameter, whereas the particles of the ripened material are spindle-shaped, $50-60 \mathrm{~nm}$ wide and $200+\mathrm{nm}$ long. The latter morphology is typical of the natural iron oxide goethite (14).

Comparison of Extraction Results. Dissolved $\mathrm{U}$ and $\mathrm{Fe}$ were not detected $\left(5 \times 10^{-10}\right.$ and $1 \times 10^{-4} \mathrm{~mol} / \mathrm{L}$, respectively) at any sampling event indicating that these elements were either associated with the surface of the precipitate or incorporated into the solid phase. The fraction of $U$ and Fe extracted from the $\mathrm{U}-\mathrm{HFO}$ coprecipitate ripened for 1 month and 2 years is shown in Figure 1. In general, the data illustrate a positive correlation of the fractions of $U$ extracted from the solid as the duration of extraction is increased (Figures 1a and 1c). There was no detectable $\mathrm{U}$ extracted by the $\mathrm{CN}$ solution. The Am-Ox extractant demonstrated very aggressive extraction behavior, and the other solutions exhibited intermediate behavior. The rate and extent of $U$ extraction from the coprecipitate ripened for 2 years is significantly less than that ripened for 1 month. Figures $1 \mathrm{~b}$ and $1 \mathrm{~d}$ show the relationship of extracted $U$ and Fe. The fact that all data points are above the line of congruent extraction indicates that $U$ is preferentially removed from the solid. In the case of the CARB solution, only $U$, and no detectable Fe, was extracted. The coprecipitate ripened for 1 month was quantitatively dissolved by the Am-Ox solution within $5 \mathrm{~min}$, but only $33 \%$ of the Fe and $63 \%$ of the $U$ was extracted in $24 \mathrm{~h}$ from the coprecipitate that had ripened for 2 years. These results suggest that significant transformation of the 

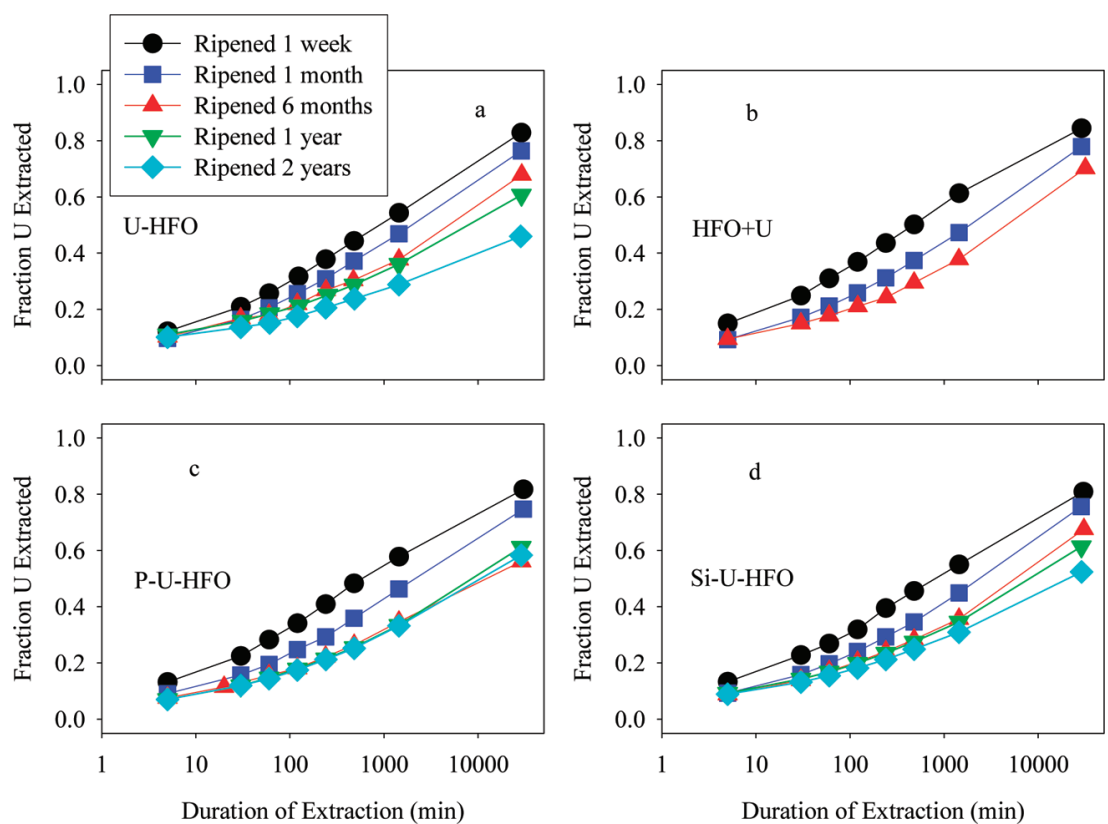

FIGURE 3. Uranium extracted from four HFOs using the CARB extractant as mineral ripening progresses: (a) U-HFO coprecipitate, (b) $\mathrm{U}$ added after HFO precipitation, (c) P-U-HFO coprecipitate, and (d) Si-U-HFO coprecipitate.

solid from an amorphous to crystalline material has occurred during this period. An alternate explanation for the comparative differences in $U$ and Fe extraction may be attributed to the wide variation in $\mathrm{pH}$ of the solutions. For example, the Am-Ox solution is acidic ( $\mathrm{pH} \sim 3.3)$, while the CARB extractant is basic ( $\mathrm{pH} \sim 9.4$ ), and concentrations of dissolved Fe in the high $\mathrm{pH}$, carbonate-containing solution are not detectable by the methods used in this work. Thermodynamic modeling of the CARB extraction of the U-HFO using MINTEQ (30) predicts $\mathrm{Fe}(\mathrm{III})_{\mathrm{aq}}$ of $2.3 \times 10^{-11} \mathrm{~mol} / \mathrm{L}$ in equilibrium with ferrihydrite. In the CARB extract, it is possible that slow dissolution of the solids occurs, which allows the U to complex with carbonate, forming stable aqueous species, but causes rapid reprecipitation of a U-depleted HFO. Conceptually

$$
\begin{aligned}
\mathrm{U}-\mathrm{HFO}_{(\mathrm{s})}+\mathrm{H}_{2} \mathrm{O}+\mathrm{HCO}_{3}^{-}(\mathrm{aq}) \leftrightarrow & \underset{\mathrm{HFO}}{(\mathrm{s})}+ \\
& \mathrm{U}-\text { carbonate }_{(\mathrm{aq})} \text { complex }
\end{aligned}
$$

The AA + CN extraction of the U-HFO ripened for 2 years displayed preference for $U$ extraction at short contact time (60-120 $\mathrm{min}$ ) before the dissolution of increasing quantities of Fe oxide at longer times (480-1440 min). This relationship is illustrated in Figures $1 \mathrm{c}$ and $1 \mathrm{~d}$ where the proportion of U extracted increased only slightly from $42 \%$ to $46 \%$ between 8 and $24 \mathrm{~h}$ while the fraction of Fe extracted increased from $8 \%$ to $18 \%$. This may be an indication that there is a time threshold before the semicrystalline mineral phases are dissolved by this extractant. The results of the HAH and AA $+\mathrm{CN}$ extractions may provide some insight into the nature of $U$ association with the solids. The shorter extraction periods $(\leq 120 \mathrm{~min})$ in either solution resulted in a much higher fraction of $U$ extracted than Fe. Thus, beyond a certain point, large increases in mineral dissolution result in only a small fraction of additional extracted $U$. These data suggest that the $U$ is heterogeneously associated with the iron oxide. A possible explanation is that the majority of $U$ is associated near the HFO surface in a relatively amorphous structure with a minor proportion distributed throughout the bulk solid. The Fe extraction data is further discussed in the Supporting Information.
Extraction Comparison of the HFO + U with Coprecipitated $\mathbf{U}-\mathbf{H F O}$. The $\mathrm{U}$ extracted from the U-HFO coprecipitate and the material where $U$ was added after HFO precipitation ( $\mathrm{HFO}+\mathrm{U}$ ) using the CARB solution is shown in Figure 2. The data show that a small proportion $(10 \%-15 \%)$ of $U$ is extracted within $5 \mathrm{~min}$ and gradually increases as the extraction period increases, suggesting that a small portion of the $U$ is rapidly extracted but additional $U$ is also in an extractable form. After ripening for 1 week, a slightly greater fraction of $U$ was extracted from the $\mathrm{HFO}+\mathrm{U}$ compared to the U-HFO coprecipitate at each sampling time. However, after 1 month, the fraction of $U$ extracted from each material was nearly identical. These results suggest that initially the $\mathrm{U}$ is associated with the two materials somewhat differently, i.e., the proportion of surface-associated $U$ is greater in the $\mathrm{HFO}+\mathrm{U}$ suspension than the U-HFO coprecipitate, and are consistent with the hypothesis that a higher proportion of $U$ is associated with surface sites accessible to the extracting solution in the fresh HFO + U. In the case of the coprecipitated system, uranyl incorporation into the bulk solid and surface sorption may occur. However, in the system where the HFO is precipitated prior to U introduction, only surface sorption mechanisms should occur initially. As a consequence of mineral ripening, it is possible that diffusion of $U$ into the solid or incorporation into the bulk structure during particle aggregation or crystal growth has occurred. Alternatively, subtle differences between the mineral particles initially in the two systems, such as surface area, may explain these results. Furthermore, the gradual increase of U extracted as the extraction period increases suggest that the application of bulk extraction techniques to generate data that may distinguish subtle differences in $U$ chemical forms and mineral associations is likely a futile endeavor.

U Extraction Behavior. The fraction of $U$ extracted from the $\mathrm{U}-\mathrm{HFO}, \mathrm{P}-\mathrm{U}-\mathrm{HFO}$, and $\mathrm{Si}-\mathrm{U}-\mathrm{HFO}$ using the CARB solution after ripening for 1 week, 1 month, 6 months, 1 year, and 2 years is shown in Figure 3 . The rate of $U$ extractability tends to decrease as ripening progresses. The extractability of $\mathrm{U}$ from the $\mathrm{P}-\mathrm{U}-\mathrm{HFO}$ coprecipitate ripened for 6 months, 1 year, and 2 years is similar from 5 to 1440 min extraction time. However, the fraction of $U$ extracted in 20 days from 

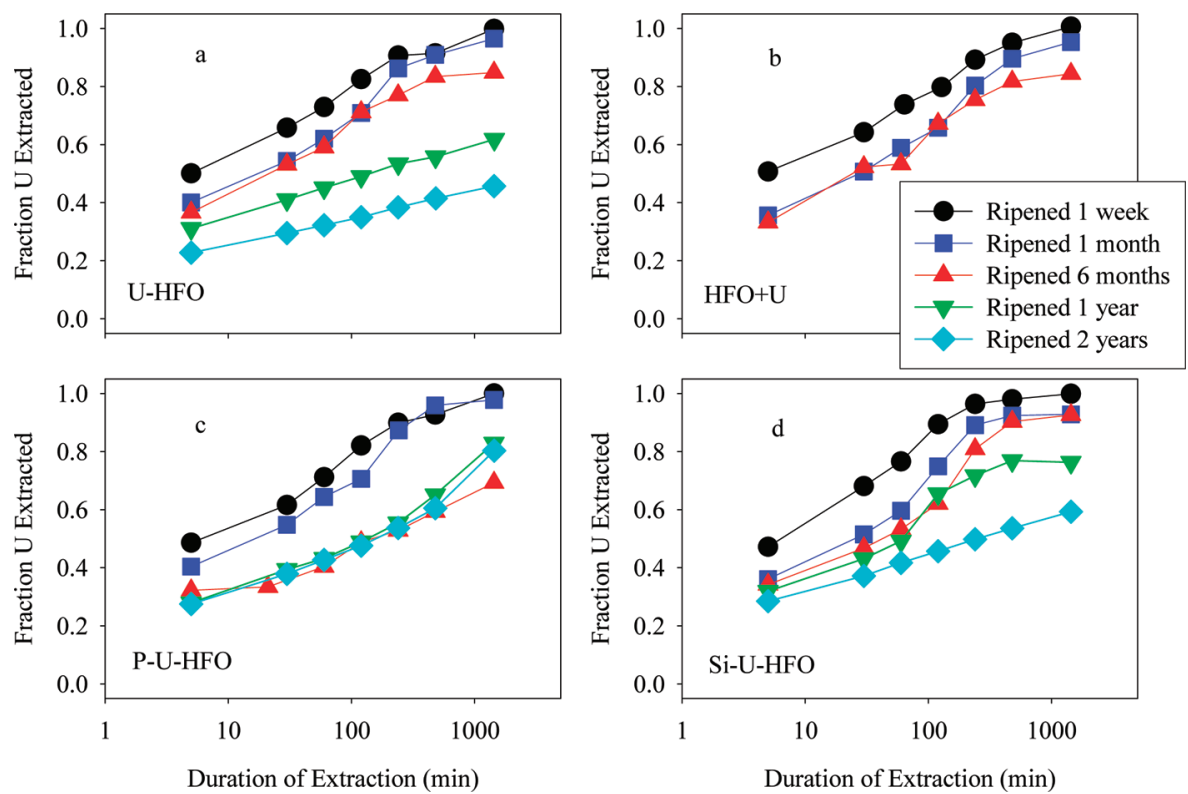

FIGURE 4. Uranium extracted from four HFOs using the AA + CN extractant as mineral ripening progresses: (a) U-HFO coprecipitate, (b) U added after HFO precipitation, (c) P-U-HFO coprecipitate, and (d) $\mathrm{Si}-\mathrm{U}-\mathrm{HFO}$ coprecipitate.
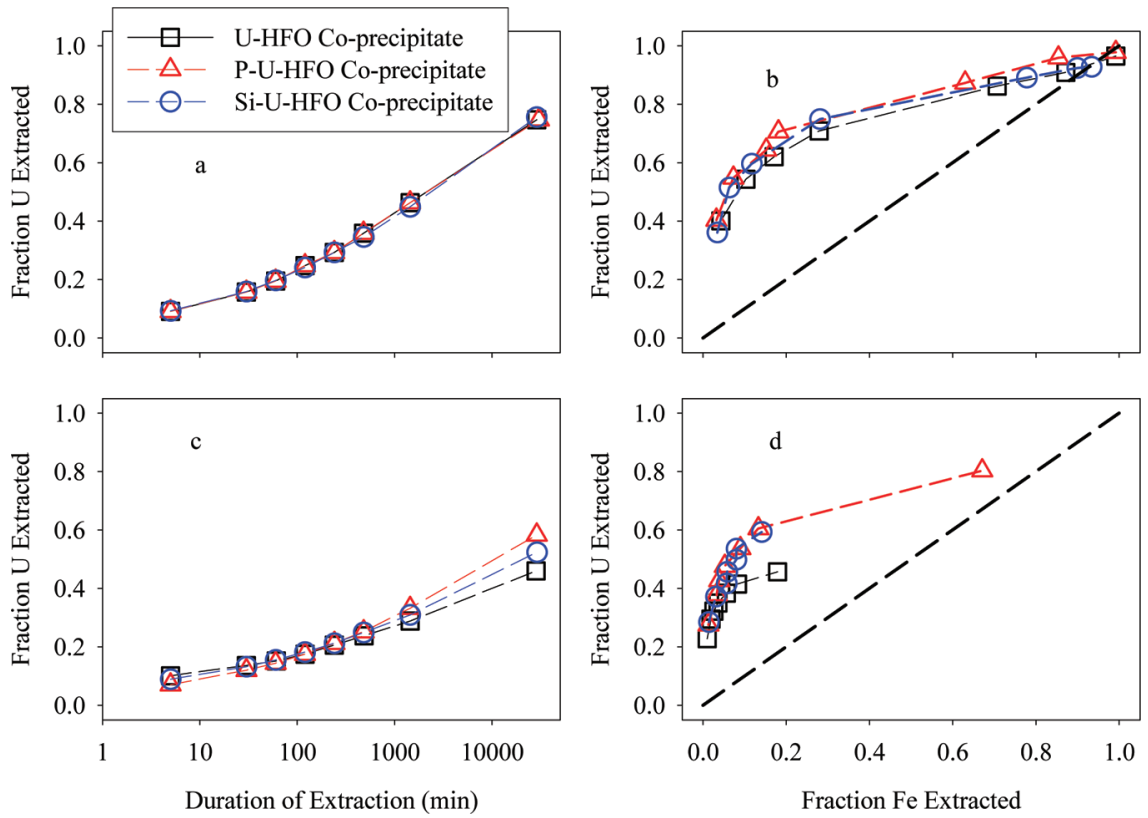

FIGURE 5. Uranium extracted from three HFOs using the CARB extractant $(a, c)$ and uranium and iron extracted using the AA + CN extractant (b, d) after 1 month $(a, b)$ and 2 years (c, d) of mineral ripening. The diagonal dashed lines in (b) and (d) indicate congruent extraction.

the material ripened for 6 months $(0.561 \pm 0.007,1$ standard deviation based on three replications) was somewhat less than the amount extracted from the material ripened for 1 year $(0.612 \pm 0.017)$. The fractions of $U$ extracted from the solids range from approximately $10 \%$ after a 5 min extraction up to $50 \%-80 \%$ in 20 days. Interestingly, the fraction of $U$ extracted from each of the coprecipitates in 5 min using the CARB solution consistently remains near $10 \%$ as ripening progresses. These results suggest that a constant proportion of $U$ is associated with the surface in a stable chemical form that is readily extractable, which contrasts with the AA $+\mathrm{CN}$ extraction data (Figure 4, discussed in the next paragraph). The strong time-dependent extractability of $U$ using the CARB solution could be the result of two mechanisms: (1) interaction of the nonaggressive extractant with the $U$ in the solid phase resulting in a slow diffusion of $U$ from the solid, or (2) gradual dissolution of the coprecipitate resulting in the release of $U$ into solution where it becomes complexed by the carbonate ligand with concomitant reprecipitation of a U-depleted Fe hydroxyoxide or Fe carbonate phase.

The extractability of $U$ by the AA + CN solution is shown in Figure 4. The fraction of $U$ extracted from the HFOs ripened for 1 week is $100 \%$ after the 1440 min extraction and decreases as mineral ripening occurs. In the $\mathrm{U}-\mathrm{HFO}, \mathrm{HFO}+\mathrm{U}$, and $\mathrm{Si}-\mathrm{U}-\mathrm{HFO}$ systems, the fraction of $\mathrm{U}$ extracted at $1440 \mathrm{~min}$ decreases significantly as mineral ripening progresses. 
However, U extracted from the $\mathrm{P}-\mathrm{U}-\mathrm{HFO}$ at $1440 \mathrm{~min}$ exhibited results inconsistent with linearly progressive ripening. These results may be explained by the formation of a transitory phase between 1 and 6 months of ripening that is relatively resistant to $U$ extraction, that upon further transformation forms a phase with greater U extractability. The fraction of $U$ extracted from the coprecipitates ranges from approximately $30 \%$ after a 5 min contact up to $100 \%$. This extractant is somewhat more aggressive than the CARB solution, resulting in progressive dissolution of the mineral phase, further discussed in the Supporting Information.

Comparison of $\mathbf{U}-$ HFO Systems Coprecipitated with Either Si or P. The fraction of $U$ and Fe extracted from the $\mathrm{U}-\mathrm{HFO}, \mathrm{P}-\mathrm{U}-\mathrm{HFO}$, and $\mathrm{Si}-\mathrm{U}-\mathrm{HFO}$ coprecipitates 1 month and 2 years after initial precipitation is shown in Figure 5. The $U$ extracted by the CARB solution after 1 month ripening (Figure 5a) is quite similar for all materials. However, after ripening for 2 years, the relative order of $U$ extractability was $\mathrm{U}-\mathrm{HFO}<\mathrm{Si}-\mathrm{U}-\mathrm{HFO}<\mathrm{P}-\mathrm{U}-\mathrm{HFO}$ (Figure $5 \mathrm{c}$ ). The proportions of $\mathrm{U}$ and $\mathrm{Fe}$ extracted by the $\mathrm{AA}+\mathrm{CN}$ solution are shown in Figures $5 \mathrm{~b}$ and $5 \mathrm{~d}$. In this case, $U$ is preferentially extracted and the extractability of $U$ and $F e$ is much reduced after 2 years of ripening. Based on Fe extraction data, the $\mathrm{P}-\mathrm{U}-\mathrm{HFO}$ is more susceptible to dissolution than are the $\mathrm{U}-\mathrm{HFO}$ and $\mathrm{Si}-\mathrm{U}-\mathrm{HFO}$. An explanation for the observed trend is that the presence of either Si or P in the coprecipitate perturbs the mineral structure resulting in solid phases that are more susceptible to dissolution by the extractants and conditions of this study. Further investigations that define the structural properties of the minerals during transformation; i.e., crystallinity, structural distribution of Fe, Si or P, and $U$, and bonding environment, could explain this trend.

The experimental studies reported here were performed to test the hypothesis that $U$ extractability from freshly prepared HFO decreases as the duration of its association with the solid increases. The results are consistent with this hypothesis, as discussed above and shown in Figures 1 and $3-5$. It is important to note that these results were obtained under controlled laboratory conditions, and their application to environmental systems requires validation. Conditions in the environment are much more complicated and dynamic than those in this simple laboratory system and could have a significant influence on the fate of $U$ beyond which would be expected based on extrapolation of results from these experiments. Additional studies are needed to ascertain more about the mechanism(s) of $U$ association with HFO at different time periods of aging and encompassing the broader range of possible conditions of particular environmental systems.

\section{Acknowledgments}

This research was supported by the U.S. Department of Energy (DOE) Office of Nonproliferation Research and Development. Mössbauer and micro-XRD measurements were performed at the W. R. Wiley Environmental Molecular Sciences Laboratory (EMSL), a DOE national scientific user facility. PNNL is operated for DOE by Battelle.

\section{Supporting Information Available}

Additional details of the materials and methods used for preparing samples for SEM, Mössbauer spectroscopy, and micro-X-ray diffraction analysis and discussion of the results are presented in the SI. The results of iron extractability from the HFOs as a function of mineral ripening are also presented and discussed. This information is available free of charge via the Internet at http://pubs.acs.org.

\section{Literature Cited}

(1) Thomas Jefferson National Accelerator Facility-Office of Science Education. http://www.education.jlab.org/itselemental/ele092, accessed 31 July, 2008.
(2) Zachara, J. M.; Davis, J. A.; McKinley, J. P.; Wellman, D.; Liu, M. C.; Qafoku, N.; Yabusaki S. B. Uranium geochemistry in vadose zone and aquifer sediments from the 300 Area uranium plume. PNNL-15121, 2005.

(3) Zachara, J. M.; Brown, C.; Christensen, J.; Davis, J. A.; Dresel, E.; Kelly, S.; Liu, C.; McKinley, J.; Serne, J.; Um, W. A site-wide perspective on uranium geochemistry at the Hanford Site. PNNL-17031, 2007.

(4) Crancon, P.; van der Lee, J. Speciation and mobility of uranium(VI) in humic-containing soils. Radiochim. Acta 2003, 91, 673-679.

(5) Oda, J.; Ohyshi, A. Complex formation between the uranyl ion and citric acid. Bull. Chem. Soc. Jpn. 1975, 48, 227-229.

(6) Fox, P. M.; Davis, J. A.; Zachara, J. M. The effect of calcium on aqueous uranium(VI) speciation and adsorption to ferrihydrite and quartz. Geochim. Cosmochim. Acta 2006, 70, 1379-1387.

(7) Lenhart, J. J.; Cabaniss, S. E.; MacCarthy, P.; Honeyman, B. D. Uranium U(VI) complexation with citric, humic and fulvic acids. Radiochim Acta. 2000, 88, 345-353.

(8) Uranium: Mineralogy, Geochemistry, and the Environment; Burns, P. C., Finch, R., Eds.; Mineralogical Society of America: Washington, D.C., 1999; 679 pp.

(9) Catalano, J. G.; McKinley, J. P.; Zachara, J. M.; Heald, S. M.; Smith, S. C.; Brown, G. E. Changes in uranium speciation through a depth sequence of contaminated Hanford sediments. Environ. Sci. Technol. 2006, 40, 2517-2524.

(10) Ohnuki, T.; Isobe, H.; Yanase, N.; Nagano, T.; Sakamoto, Y.; Sekine, K. Change in sorption characteristics of uranium during crystallization of amorphous iron minerals. J. Nucl. Sci. Technol. 1997, 34, 1153-1158.

(11) Arai, Y.; Marcus, M. A.; Tamura, N.; Davis, J. A.; Zachara, J. M. Spectroscopic evidence for uranium bearing precipitates in vadose zone sediments at the Hanford 300-Area site. Environ. Sci. Technol. 2007, 41, 4633-4639.

(12) Giammar, D. E.; Hering, J. G. Time scales for sorption-desorption and surface precipitation of uranyl on goethite. Environ. Sci. Technol. 2001, 35, 3332-3337.

(13) Stubbs, J. E.; Elbert, D. C.; Veblen, D. R.; Zhu, C. Electron microbeam investigation of uranium-contaminated soils from Oak Ridge, TN, USA. Environ. Sci. Technol. 2006, 2108-2113.

(14) Allard, T.; Ildefonse, P.; Beaucaire, C.; Calas, G. Structural chemistry of uranium associated with $\mathrm{Si}, \mathrm{Al}$, Fe gels in a granitic uranium mine. Chem. Geol. 1999, 158, 81-103.

(15) Duff, M. C.; Urbanik-Coughlin, J.; Hunter, D. B. Uranium coprecipitation with iron oxide minerals. Geochim. Cosmochim. Acta 2002, 66, 3533-3547.

(16) Bolton, E. W.; Lasaga, A. C.; Rye, D. M. Long-term flow/chemistry feedback in a porous medium with heterogeneous permeability: kinetic control of dissolution and precipitation. Am. J. Sci. 1999, 299, 1-68.

(17) Buck, E. C.; Brown, N. R.; Dietz, N. L. Contaminant uranium phases and leaching at the Fernald site in Ohio. Environ. Sci. Technol. 1996, 30, 81-88.

(18) Jönsson J. Phase transformations and surface chemistry of secondary iron minerals formed from acid mine drain. Ph.D. Dissertation, Umeå University, Sweden, 2003.

(19) Kukkadapu, R. K.; Zachara, J. M.; Fredrickson, J. K.; Smith, S. C.; Dohnalkova, A. C.; Russell, C. K. Transformation of 2-line ferrihydrite to 6 -line ferrihydrite under oxic and anoxic conditions. Am. Mineral. 2003, 88, 1903-1914.

(20) Stoffregen, R. Numerical simulation of mineral-water isotope exchange via Ostwald ripening. Am. J. Sci. 1996, 296, 908-931.

(21) Morse, J. W.; Casey, W. H. Ostwald processes and mineral paragenesis in sediments. Am. J. Sci. 1988, 288, 537-560.

(22) Ford, R. G.; Bertsch, P. M.; Farley, K. J. Changes in transition and heavy metal partitioning during hydrous iron oxide aging. Environ. Sci. Technol. 1997, 31, 2028-2033.

(23) Ainsworth, C. C.; Pilon, J. L.; Gassman, P. L.; Van Der Sluys, W. G. Cobalt, cadmium, and lead sorption to hydrous oxide: residence time effect. Soil Sci. Soc. Am. J. 1994, 58, 1615-1623.

(24) Tessier, A.; Campbell, P. G. C.; Bisson, M. Sequential extraction procedure for the speciation of particulate trace metals. Anal. Chem. 1979, 51, 844-851.

(25) Bacon, J. R.; Davidson, C. M. Is there a future for sequential chemical extraction? Analyst 2008, 133, 25-46.

(26) Bruno, J.; De Pablo, J.; Duro, L.; Figuerola, E. Experimental study and modeling of the $\mathrm{U}(\mathrm{VI})-\mathrm{Fe}(\mathrm{OH}) 3$ surface precipitation/ coprecipitation equilibria. Geochim. Cosmochim. Acta 1995, 59, 4113-4123.

(27) Zachara, J. M.; Girvin, D. C.; Schmidt, R. L.; Resch, C. T. Chromate adsorption on amorphous iron oxyhydroxide in the presence 
of major groundwater ions. Environ. Sci. Technol. 1987, 21, 589594.

(28) Sowder, A. G.; M Bertsch, P.; Morris, P. J. Partitioning and availability of uranium and nickel in contaminated riparian sediments. J. Environ. Qual. 2003, 32, 885-898.

(29) Kohler, M.; P Curtis, G.; Meece, D. E.; Davis, J. A. Methods for estimating adsorbed $\mathrm{U}(\mathrm{VI})$ and distribution coefficients of contaminated sediments. Environ. Sci. Technol. 2004, 38, 240247.

(30) Gustafsson, J. P. Visual MINTEQ, ver. 2.32; Royal Institute of Technology (KTH), Department of Land and Water Resources Engineering: Stockholm, Sweden, 2005.
(31) Schwertmann U.; Cornell R. M. Iron oxides in the laboratory: preparation and characterization; VCH: New York, 1991.

(32) Gálvez, N.; Barrón, V.; Torrent, J. Effect of phosphate on the crystallization of hematite, goethite, and lepidocrocite from ferrihydrite. Clays Clay Miner. 1999, 47, 304-311.

(33) Janot, C.; Gilbert, H.; Tobias, C. Caracterisation de kaolinites ferriferes par spectrometrie Mossbauer. Bull. Soc. Fr. Miner. Cristall. 1973, 96, 281-291.

ES802621T 